\title{
Phylogenetic, epidemiological and functional analyses of the Streptococcus bovis/Streptococcus equinus complex through an overarching MLST scheme
}

Christoph Jans ${ }^{1}$, Tomas de Wouters ${ }^{1}$, Bassirou Bonfoh², Christophe Lacroix ${ }^{1}$, Dasel Wambua Mulwa Kaindi ${ }^{3}$ Janine Anderegg ${ }^{1}$, Désirée Böck', Sabrina Vitali ${ }^{1}$, Thomas Schmid ${ }^{1}$, Julia Isenring ${ }^{1}$, Fabienne Kurt',

Wambui Kogi-Makau ${ }^{3}$ and Leo Meile ${ }^{1 *}$

\begin{abstract}
Background: The Streptococcus bovis/Streptococcus equinus complex (SBSEC) comprises seven (sub)species classified as human and animal commensals, emerging opportunistic pathogens and food fermentative organisms. Changing taxonomy, shared habitats, natural competence and evidence for horizontal gene transfer pose difficulties for determining their phylogeny, epidemiology and virulence mechanisms. Thus, novel phylogenetic and functional classifications are required. An SBSEC overarching multi locus sequence type (MLST) scheme targeting 10 housekeeping genes was developed, validated and combined with host-related properties of adhesion to extracellular matrix proteins (ECM), activation of the immune responses via NF-KB and survival in simulated gastric juice (SGJ).

Results: Commensal and pathogenic SBSEC strains $(n=74)$ of human, animal and food origin from Europe, Asia, America and Africa were used in the MLST scheme yielding 66 sequence types and 10 clonal complexes differentiated into distinct habitat-associated and mixed lineages. Adhesion to ECMs collagen I and mucin type II was a common characteristic (23\% of strains) followed by adhesion to fibronectin and fibrinogen (19.7\%). High adhesion abilities were found for East African dairy and human blood isolate branches whereas commensal fecal SBSEC displayed low adhesion. NF-KB activation was observed for a limited number of dairy and blood isolates suggesting the potential of some pathogenic strains for reduced immune activation. Strains from dairy MLST clades displayed the highest relative survival to SGJ independently of dairy adaptation markers lacS/lacZ.

Conclusion: Combining phylogenetic and functional analyses via SBSEC MLST enabled the clear delineation of strain clades to unravel the complexity of this bacterial group. High adhesion values shared between certain dairy and blood strains as well as the behavior of NF-KB activation are concerning for specific lineages. They highlighted the health risk among shared lineages and establish the basis to elucidate (zoonotic-) transmission, host specificity, virulence mechanisms and enhanced risk assessment as pathobionts in an overarching One Health approach.
\end{abstract}

Keywords: Streptococcus infantarius, Streptococcus macedonicus, Streptococcus gallolyticus, One health, Adhesion, Inflammation, Colorectal cancer, Foodborne disease, Infective endocarditis, Pathobiont

\footnotetext{
* Correspondence: leo.meile@hest.ethz.ch

'Laboratory of Food Biotechnology, Institute of Food, Nutrition and Health,

ETH Zurich, Schmelzbergstrasse 7, 8092 Zurich, Switzerland

Full list of author information is available at the end of the article
} 


\section{Background}

The Streptococcus bovis/Streptococcus equinus complex (SBSEC) is a highly diverse group of bacteria that includes human and animal commensals, opportunistic pathogens and organisms that contribute to traditional food fermentations [1, 2]. The complex currently comprises the species Streptococcus gallolyticus subsp. gallolyticus (Sgg), Streptococcus gallolyticus subsp. pasteurianus (Sgp), Streptococcus gallolyticus subsp. macedonicus (Sgm), Streptococcus infantarius subsp. infantarius (Sii), Streptococcus lutetiensis (previously Streptococcus infantarius subsp. coli), Streptococcus alactolyticus and a remaining group of strains originally described as S. equinus and $S$. bovis which are allocated to $S$. equinus $[1,2]$.

SBSEC are commensal colonizers of the human and animal gastrointestinal tract (GI tract). The carriage rate in humans is estimated at $23.8 \%$ in neonates in the UK [3] and around $5 \%$ in adults in France and the UK, which corresponds to the decreasing relative abundance of streptococci in the gut microbiota during aging [3-5]. SBSEC are also highly prevalent among most domesticated and wild animals, including ruminants such as cattle, goats, sheep, deer and camels. Their habitat also extends to bears, piglets, rodents, dogs, sea otters and birds [1].

The SBSEC has been associated with a variety of diseases such as infective endocarditis (IE), bacteremia, biliary tract and prosthetic joint infections as well as meningitis and diarrhea in humans or ruminal acidosis, bloat and laminitis in animals [1]. These diseases are associated with specific (sub)species within the SBSEC such as Sgg for IE and bacteremia or Sgp and S. lutetiensis for infant meningitis, biliary and urinary tract infections [1]. In addition, $S$. bovis has been linked to cancer; specifically $S$. bovis biotype I (=Sgg) has been linked to colorectal cancer (CRC) in humans [6] and possibly $S$. lutetiensis to non-colonic cancer [7]. In contrast, Sgm and Sii play a predominant role in traditional fermented food products of animal and plant origin in Southern Europe, Africa, Asia and North America, indicating the large spectrum of roles and potential public health risks by members of the SBSEC to cause diseases $[1,8,9]$.

SBSEC-related factors to cause disease, their associated virulence mechanisms, infection routes, population structure and epidemiology are however not yet elucidated. Pilus proteins encoded in a pil1-operon of Sgg are an important virulence factor responsible for adhesion to damaged tissues of heart valves and adenocarcinomas in the colon [10-12]. Furthermore, potential pro-inflammatory proteins [13] were identified in S. infantarius NCTC8133 (=CCUG4214), which suggests involvement in CRC development [14]. Shared strain lineages between food products, animals and humans suggest a zoonotic potential and possible infection route via food and fecal-oral transmission $[15,16]$, which agrees with increased SBSEC-related incidences in rural areas [17]. However, a lack of reliable molecular epidemiological tools and marker genes hinder accurate differentiation of SBSEC subspecies and their individual risk assessments, disease association and the differentiation between commensal and pathogenic subspecies or strain lineages. This difficulty is mainly due to the high degree of gene conservation among members of the SBSEC in combination with evidence of horizontal gene transfer between SBSEC and other streptococci $[18,19]$, the ability of SBSEC to be naturally competent $[19,20]$, rapidly changing taxonomy and a broad range of strains from potential food-grade, to commensal and pathogenic organisms fitting the emerging pathobiont concept [21]. The SBSEC therefore requires a holistic approach to elucidate the phylogeny, epidemiology and pathogenicity of its members in relation to their animal, human and food habitats.

Multi locus sequence typing (MLST) has been used to assess global epidemiology and strain lineages based on the combined analysis of short DNA sequences of housekeeping genes [22]. Recently, two such MLST schemes were developed for $S g g$ on different sets of seven housekeeping genes $[15,16]$. However, these MLST schemes were not designed to capture the entire SBSEC.

In this study, we aimed to develop an overarching SBSEC MLST scheme based on 10 housekeeping genes. The novel MLST scheme was clustered with phenotypic data of strains, including their survival in simulated gastric conditions, adhesion to extracellular matrix proteins of the human intestinal epithelium and NF-kB activation capacity, all of which are important parameters to evaluate intestinal bacteria and characterize potential pathogens.

\section{Methods}

\section{Bacterial strains and growth conditions}

SBSEC strains $(n=74)$ were used in this study. Of these, 58 originated from the American Type Culture Collection (ATCC, Manassas, VA, USA), the University of Gothenburg (CCUG, Gothenburg, Sweden), Deutsche Sammlung für Mikroorganismen und Zellkulturen (DSMZ, Braunschweig, Germany) and donated by other researchers while 16 strains were analyzed in silico using genome sequences available on GenBank [Additional file 1] [23-27]. African strains were selected from our own culture collection (Laboratory of Food Biotechnology, ETH Zurich, Zurich, Switzerland). These strains were isolated from fermented dairy products of cow, camel and goat origin as predominant organisms at $10^{8}$ colony forming units (CFU) $\mathrm{mL}^{-1}$ [Additional file 1] [28-30].

All enterococci and streptococci strains were cultured aerobically overnight in Brain Heart Infusion (BHI, Biolife, Milan, Italy) or M17 broth (Biolife) at $37{ }^{\circ} \mathrm{C}$, except Streptococcus thermophilus, which was cultured in M17 
broth (Biolife) at $42-43{ }^{\circ} \mathrm{C}$. Lactobacilli were grown anaerobically overnight in MRS Tween 80 broth (Biolife) supplemented with $0.05 \% \mathrm{w} / \mathrm{w}$ L-cysteine hydrochloride (MRS-C). MRS-C agar was incubated at $37{ }^{\circ} \mathrm{C}$ for 2 days. The purity of strains was checked by microscopy, streak plating and rep-PCR fingerprinting as previously described [29]. Stocks were kept in $33 \%$ (v/v) glycerol solution at $-80{ }^{\circ} \mathrm{C}$.

All chemicals, proteins and enzymes were obtained from Sigma-Aldrich (Buchs, Switzerland) unless noted otherwise.

\section{DNA isolation and PCR assays for bacterial identification}

DNA was isolated from single colonies on agar media via a short lysis in Triton X-100-based buffer at $95{ }^{\circ} \mathrm{C}$ [31]. All primers for PCR amplification and Sanger sequencing were obtained from Microsynth (Balgach, Switzerland). PCR reactions, visualization via gel electrophoresis and analyses of rep-PCR fingerprints were performed as previously described [29]. Sanger sequencing was performed at GATC (Konstanz, Germany) and Microsynth (Switzerland). General 16S rRNA gene amplification was performed using bak11w and bak4 primers [28].

All strains originating from our culture collection were previously identified by rep-PCR fingerprinting, $16 \mathrm{~S}$ rRNA gene assay and by a PCR assay targeting genes groES/groEL for some representative strains [31, 32]. All strains from external sources were identified using a novel groEL-sequencing approach, with primers groELfw and groEL-rev for amplification and sequencing that were designed based on ClustalW-aligned groEL sequences derived from all available SBSEC genomes [Additional file 2]. These novel primers target conserved binding sites within groEL and amplify a 1167-bp product. The groEL PCR assay consisted of 2 min at $95{ }^{\circ} \mathrm{C}$, followed by 35 cycles of $30 \mathrm{~s}$ at $95{ }^{\circ} \mathrm{C}, 30 \mathrm{~s}$ at $60{ }^{\circ} \mathrm{C}, 60 \mathrm{~s}$ at $72{ }^{\circ} \mathrm{C}$ and final replication for $7 \mathrm{~min}$ at $72{ }^{\circ} \mathrm{C}$.

\section{Presence of lacS/lacZ as marker genes for adapted lactose metabolism}

$l a c S$ and $l a c Z$ with high sequence identity to $S$. thermophilus/S. salivarius were shown to be marker genes for dairy adaptation for African variants of Sii [29]. The presence of these two genes in SBSEC strains was assessed and assigned to MLST clusters. Primer pairs lacZ6.2/lacZ-17rev and lacS-8/lacS-18.1rev [Additional file 2] were used as previously described [33], resulting in the amplification of approx. $1 \mathrm{~kb}$ of the lac $Z$ and 501 bp of the lacS gene [33].

\section{Multi locus sequence typing \\ Selection of target genes/loci}

The MLST scheme candidate target genes were first selected and evaluated based on genes used in the MLST- schemes for Streptococcus pneumoniae, Streptococcus suis, Streptococcus agalactiae, Streptococcus uberis, Streptococcus zooepidemicus and the salivarius group in addition to several novel candidate loci [Additional file 3] [34-39]. Thirty potential loci for initial in silico analysis from SBSEC genomes were identified using CLC Genomic Workbench (version 7.5, Qiagen Aarhus A/S, Denmark). Sequences for each locus were aligned using Bioedit, and compared to establish a phylogenetic tree and a sequence identity matrix using MEGA 5.0 [40]. Ten target loci were chosen on the basis of maximal nucleotide divergence (0.01-16.2 \%) within a highly conserved sequence (83.8$100 \%)$ to enable intra- and inter-species differentiation [Additional file 3]. Potential forward and reverse primer binding sites were selected within conserved regions and a distance of approximately 400-500 bp. All primers were designed with a length of 18-22-bp [Additional file 2]. All primers were also used for Sanger sequencing of the amplified DNA fragments. Primers for glucokinase gene amplification were optimized for S. alactolyticus using glucokinase sequences of related streptococci to develop degenerate primers. A uniform PCR amplification protocol was used, with an initial denaturation at $95{ }^{\circ} \mathrm{C}$ for $3 \mathrm{~min}$, followed by 35 cycles of $30 \mathrm{~s}$ each at $95{ }^{\circ} \mathrm{C}, 59{ }^{\circ} \mathrm{C}$ and $72{ }^{\circ} \mathrm{C}$. Final polymerization was performed at $72{ }^{\circ} \mathrm{C}$ for $7 \mathrm{~min}$.

\section{Establishment of allelic profiles and sequence types for SBSEC isolates}

Sequencing reactions for all ten loci were performed on both strands using the same primers as for the initial PCR amplification [Additional file 2]. Sequencing chromatograms were proofread, corrected and assembled using CLC Genomic Workbench. Whole genome sequences of SBSEC isolates obtained from GenBank [Additional file 1] were processed in silico using the corresponding SBSEC MLST primers to locate and extract the desired gene sequences. Sequences for each gene were then aligned in MEGA 5.0 using the ClustalW multiple alignment algorithm and trimmed to equal lengths. For each locus, the sequences of all tested isolates were compared and allele numbers were assigned to each unique sequence using CLC Genomic Workbench. Every isolate was hereby defined by a series of ten integers, constituting its allelic profile. Each unique allelic profile was subsequently assigned as the multilocus sequence type (ST) of a strain.

The diversity within each allele was visualized using the SplitsTree 4 software package and aligned sequence files processed by UncorrectedP and Neighbor-Net algorithms [41].

\section{Determination of genetic relationships among isolates by computational analysis}

The relatedness of isolates was analyzed using the START2 software [42]. START2 was further used to 
determine the number of polymorphic nucleotide sites, calculate $d_{N} / d_{S}$ ratios and construct profile-based dendrograms using the neighbor-joining (NJ) algorithm. Sequence-based trees were constructed in MEGA 5.0 using the NJ algorithm and 1000 bootstrap replications. The classical and standardized index of association $\left(\mathrm{I}_{\mathrm{A}}\right.$ and $\mathrm{I}_{\mathrm{A}}^{\mathrm{S}}$ ) were calculated in START2 using only one strain per ST to avoid bias [43]. Additionally, the test of Sawyer (1989) [44] was applied to the synonymous polymorphic sites (PMS) within the alleles at each locus. Related STs were grouped using the START2 and eBURST V3 $[45,46]$ to form clonal complexes (CC). CCs were defined as groups of two or more independent isolates where each isolate had identical alleles at seven or more loci with at least one other member of the group [47]. This definition was also used to number phylogenetic tree clades and branches.

The allele profiles per locus were used to calculate the Simpson's index of diversity (SID) [48], where a value close to 1 indicates high diversity and low diversity for values close to 0 . Twice the standard deviation of the SID value was used to obtain an approximation for the $95 \%$ confidence intervals as previously described [49].

\section{Assay for simulated gastric conditions in simulated gastric juice (SGJ)}

For simulated gastric juice (SGJ) assays, strains were grown in M17 broth (Biolife), containing lactose as carbon source to mimic the carbon source of milk. S. alactolyticus DSM20728 ${ }^{\mathrm{T}}$, S. bovis DSM20480 ${ }^{\mathrm{T}}$ and $S$. equinus DSM20558 ${ }^{\mathrm{T}}$ were incubated in BHI broth (Biolife) containing glucose instead of lactose to promote growth. Bacteria cultures were standardized to an $\mathrm{OD}_{600}$ of 1.0 using $5 \mathrm{~mL}$ of phosphate-buffered saline (PBS, $\mathrm{pH}$ 6.0), which is near the optimal $\mathrm{pH}$ for growth of SBSEC [50]. The standardized bacteria suspensions were then centrifuged at $6000 \times \mathrm{g}$ for $6 \mathrm{~min}$ at $20{ }^{\circ} \mathrm{C}$. The pellet was resuspended in $5 \mathrm{~mL}$ PBS ( $\mathrm{pH} \mathrm{6.0)}$ and stored on ice for $30 \mathrm{~min}$.

SGJ was prepared using $1 \mathrm{~g}$ of $\mathrm{NaCl}$ (Merck), $0.6 \mathrm{~g}$ of pepsin from porcine source (Sigma-Aldrich), and $0.2 \mathrm{~g}$ peptone from casein (Merck) dissolved in $200 \mathrm{~mL}$ distilled $\mathrm{H}_{2} \mathrm{O}$ [51]. $\mathrm{pH}$ was adjusted to $\mathrm{pH} 3.0$ or $\mathrm{pH} 2.5$ using $5 \mathrm{M} \mathrm{HCl}$. These $\mathrm{pH}$ values were selected within the range of human gastric conditions ( $\mathrm{pH} 1-5)$ [52] allowing for adequate time-dependent survival assays over the $15 \mathrm{~min}$ experiment duration. All SGJ were filter-sterilized $(0.2 \mu \mathrm{m}$, Sartorius Stedim Biotech $\mathrm{GmbH}$, Goettingen, Germany) and stored at $4{ }^{\circ} \mathrm{C}$. Phosphate buffered saline (PBS) was prepared containing $40 \mathrm{~g} \mathrm{~L}^{-1}$ $\mathrm{NaCl}$ (Merck), $1 \mathrm{~g} \mathrm{~L}^{-1} \mathrm{KCl}$ (VWR), $7.2 \mathrm{~g} \mathrm{~L}^{-1} \mathrm{Na}_{2} \mathrm{HPO}_{4}$ (Merck), $1.2 \mathrm{~g} \mathrm{~L}^{-1} \mathrm{KH}_{2} \mathrm{PO}_{4}$ (VWR) in distilled $\mathrm{H}_{2} \mathrm{O}$, and the $\mathrm{pH}$ was adjusted to 6.0 using $5 \mathrm{M} \mathrm{HCl}$ for low $\mathrm{pH}$ stress conditions. PBS was autoclaved and stored at $4{ }^{\circ} \mathrm{C}$.
The assay was performed in sterile 96-well plates (Bioswisstec AG, Schaffhausen, Switzerland) using $270 \mu \mathrm{L}$ of SGJ or PBS ( $\mathrm{pH} 6.0)$ per well. The plates were preheated to $37{ }^{\circ} \mathrm{C}$ and inoculated with $30 \mu \mathrm{L}$ of the standardized test culture in parallel for all conditions. Plates were incubated in air-tight plastic containers to reduce evaporation. Samples were analyzed after 0, 5, 10 and 15 min of incubation at $37{ }^{\circ} \mathrm{C}$. Enumeration of surviving bacteria was done after serial dilution from $10^{-1}$ to $10^{-6}$ and microspotting of $15 \mu \mathrm{L}$ onto agar medium (M17 or BHI) with a detection limit of $2.8 \log _{10} \mathrm{CFU} \mathrm{mL} \mathrm{m}^{-1}$. The assays were performed with two biological replications each comprising three technical replications. Sii CJ18 and Sii CCUG43820 ${ }^{\mathrm{T}}$ were used as control strains in each replication. Relative survival rates per strain were calculated where the input is set at $0 \log _{10} \mathrm{CFU} \mathrm{mL} \mathrm{m}^{-1}$ and reduction is expressed in negative log-values [53]. For ease of comparison between strains at a given condition, relative survival rates of each strain were normalized using the formula $\left(\mathrm{x}_{\mathrm{i}}-\mathrm{x}_{\text {mean }}\right) / \mathrm{SD}$, where $\mathrm{x}_{\mathrm{i}}$ is the relative survival rate of a strain, $x_{\text {mean }}$ the mean relative survival rate of all strains for one condition and SD the standard deviation.

\section{Assay for bacterial adhesion to extracellular matrix proteins}

BHI broth overnight cultures were standardized to an optical density at $600 \mathrm{~nm}\left(\mathrm{OD}_{600}\right)$ of 1.0 using PBS $(\mathrm{pH} 7.5)$ and centrifuged for $10 \mathrm{~min}$ at $3000 \times \mathrm{g}$. The supernatant was discarded and the pellet resuspended in the original volume of PBS ( $\mathrm{pH} 7.5)$. The bacteria sample was then divided into two equal aliquots and centrifugation was repeated. The supernatant was discarded and one bacteria aliquot per culture was resuspended in PBS ( $\mathrm{pH} 7.5$ ) and acidified PBS ( $\mathrm{pH}$ 5.5), respectively. Aliquots were kept on ice until use.

Extracellular matrix proteins (ECM) used in this study were collagen type I (rat tail) and type IV (human cell culture), fibrinogen and fibronectin (human cell culture) and the glyco-protein mucin type II (porcine stomach). Bovine serum albumin (BSA) was used as a control protein (Sigma-Aldrich). Stock solutions of ECMs were prepared at a concentration of $10 \mu \mathrm{g} \mathrm{mL}^{-1}$ in PBS ( $\mathrm{pH} 7.5$ ) except BSA and mucin type II at $0.5 \mathrm{mg} \mathrm{mL}^{-1}$ in $0.1 \mathrm{M}$ Tris $\mathrm{HCl}$ (pH 8.0). MaxiSorp ${ }^{\mathrm{TM}}$ 96-well plates (Thermo Fischer Scientific, Reinach, Switzerland) were treated with $100 \mu \mathrm{L}$ of an ECM stock solution per well [54]. One 96-well plate was filled with $100 \mu \mathrm{L}$ of PBS (pH 7.5) as a negative adhesion control of the plastic surface. The plates were incubated overnight at $4{ }^{\circ} \mathrm{C}$. Subsequently, the liquid was poured off by plate inversion and dried for $10 \mathrm{~min}$ at $65{ }^{\circ} \mathrm{C}$. The plate surface was blocked with $100 \mu \mathrm{L}$ PBS ( $\mathrm{pH} 7.5$ ) containing $1 \%$ Tween 20, incubated for $1 \mathrm{~h}$ at $37^{\circ} \mathrm{C}$ and subsequently washed 3 times 
with $100 \mu \mathrm{L}$ PBS (pH 7.5) containing $0.05 \%$ Tween 20 . Coated plates were stored at $4{ }^{\circ} \mathrm{C}$ with $100 \mu \mathrm{L}$ PBS $(\mathrm{pH} 7.5)$ added per well. Bacteria cells $(100 \mu \mathrm{L})$ resuspended in PBS pH 7.5 or $\mathrm{pH} 5.5$ were then added to the coated 96-well plates. The inoculated plates were gently centrifuged for $10 \mathrm{~min}$ at $400 \times g$ at room temperature to enable physical contact of the bacteria with the tested proteins, and the plates were then incubated at $37{ }^{\circ} \mathrm{C}$ for $1 \mathrm{~h}$. The wells were then washed three times with $100 \mu \mathrm{L}$ PBS (pH 7.5) containing $0.05 \%$ Tween 20, and adhering bacteria were fixed for $20 \mathrm{~min}$ at $65{ }^{\circ} \mathrm{C}$. Staining was performed using crystal violet $(100 \mu \mathrm{L}$ at $1 \mathrm{mg} \mathrm{mL}{ }^{-1}$ per well) for $45 \mathrm{~min}$ at room temperature, followed by washing three times with $100 \mu \mathrm{L}$ PBS ( $\mathrm{pH}$ 7.5). Bacteria-associated crystal violet was then solubilized by adding $100 \mu \mathrm{L}$ citrate buffer $(50 \mathrm{mM}, \mathrm{pH} 4.0)$ to each well and incubating for $1 \mathrm{~h}$ at $37{ }^{\circ} \mathrm{C}$ under constant agitation at 400-500 rpm. The absorbance of crystal violet was measured at $595 \mathrm{~nm}$ (BioTeK, PowerWave $\mathrm{XS})$. The normalized cell adhesion of a strain $\left(\mathrm{x}_{\mathrm{i}}\right)$ was calculated from the mean of three independent biological repetitions, using the formula $\left(\mathrm{x}_{\mathrm{i}}-\mathrm{x}_{\text {median }}\right) / \mathrm{SD}$ [55], where $x_{\text {median }}$ and SD were obtained from the adhesion measurements of all strains under one condition. Values larger than 1 from the normalized 0 were considered to be adherent.

\section{Assay for inflammatory potential via NF-kB activation}

The activation of nuclear factor k-light-chain-enhancer of activated B cells (NF-kB) was assessed using THP1Blue $^{\mathrm{TM}}$ cells (InvivoGen/Labforce, Muttenz, Switzerland). These cells express all known Toll-like receptors and enable quantification of the NF-KB activation via the SEAP reporter gene. THP1-Blue ${ }^{\mathrm{TM}}$ cells were grown in RPMI 1640 supplemented with $2 \mathrm{mM}$ L-glutamine, $50 \mathrm{IU} \mathrm{mL}$ ${ }^{-1}$ penicillin, $50 \mu \mathrm{g} \mathrm{mL} \mathrm{m}^{-1}$ streptomycin and $10 \%$ heatinactivated fetal calf serum (FCS) in a humidified $10 \%$ $\mathrm{CO}_{2}$ atmosphere at $37{ }^{\circ} \mathrm{C}$. All culture media were supplied by Life Technologies (Zug, Switzerland). The assay was performed in 96-well plates containing $90 \mu \mathrm{L}$ of THP1-Blue ${ }^{\mathrm{Tm}}$ cells at a concentration of $2 \times 10^{4}$ cells per well. Bacteria cells were prepared by centrifugation for $5 \mathrm{~min}$ at $12,000 \times g$ of $1-\mathrm{mL}$ aliquots of bacteria cultures standardized to an $\mathrm{OD}_{600}$ of 1.0. The supernatant was transferred into a new tube and both supernatant and pellet were stored at $-20{ }^{\circ} \mathrm{C}$ until use. THP1-Blue ${ }^{\mathrm{Tx}}$ cells were activated using $10 \mu \mathrm{L}$ of the supernatant or resuspended pellet in $1 \mathrm{~mL}$ PBS. The plates were incubated for 18 to $24 \mathrm{~h}$. NF-kB activation was quantified by adding $10 \mu \mathrm{L}$ of supernatant of the stimulated THP1Blue $^{\mathrm{TM}}$ cells to $100 \mu \mathrm{L}$ QUANTI-Blue ${ }^{\mathrm{TM}}$ (InvivoGen). After 1 to $8 \mathrm{~h}$ of incubation at $37{ }^{\circ} \mathrm{C}$, SEAP activity was quantified at $655 \mathrm{~nm}$ as described by the supplier. Normalization was performed as described for the adhesion assay.

\section{Statistics}

Statistical analysis was performed in JMP11.21 (SAS Institute, Cary, NC, USA). Data was first analyzed for normal distribution using the Shapiro-Wilk-W-Test. Non-normal distribution of log-transformed values required the utilization of a Kruskal-Wallis-Test, which was upon rejection of $\mathrm{H}_{0}$ further compared in a posthoc pair-wise Wilcoxon-Test without correction for multiple comparisons [56] in order to reduce type II errors. This was complemented by graphical analysis and detection of outliers by calculating the interquartile range IQ and the defined limitations of lower fence of Q1-1.5*IQ and upper fence Q3+1.5*IQ. Strains displaying values outside of the upper or lower fence were considered outliers.

\section{Results \\ Identification of SBSEC (sub)species by groEL and $16 \mathrm{~S}$ rRNA gene sequencing}

Partial groEL sequencing was performed on all SBSEC strains to confirm species and subspecies status [Additional file 4]. All groEL nucleotide sequences were trimmed to an equal length of $772 \mathrm{bp}$ for comparison and neighbor-joining tree construction [Additional file 5]. Sii and S. lutetiensis had a maximum identity of 94.9-95.4\%, whereas none of the S. gallolyticus branch members displayed more than $91 \%$ identity to Sii. The S. gallolyticus branch was more conserved, yielding 98.8-99.2 \% or 97.7-97.9 \% between Sgm and Sgg or Sgp, respectively. Intraspecies variations were generally low, yielding 99.3-100.0\% sequence identity among strains of a single subspecies. S. equinus JB1 showed highest identity to $\mathrm{Sii}(98.1 \%)$ by groEL and $99.9 \%$ to the $S$. lutetiensis by $16 \mathrm{~S}$ rRNA gene sequence. In addition, CCUG4214 (isogenetic strain of NCTC8133), which was initially classified as $S$. bovis and subsequently reclassified as $\mathrm{Sii}$ [13], was again reclassified in this study as $S$. equinus. Similarly, S. bovis ATCC700338 was reclassified as Sgp based on groEL and $16 \mathrm{~S}$ rRNA gene sequences [Additional files 5 and 6]. Strain J2 40-2 isolated from fermented milk from Bangladesh was identified as Sgm by groEL sequencing, whereas $16 \mathrm{~S}$ rRNA gene sequence and rep-PCR fingerprinting indicated $S$. infantarius/S. equinus branch [Additional files 5 and 6].

\section{MLST loci characterization and key performance identifiers}

The MLST assay was designed as an overarching scheme to target the entire SBSEC and validate (sub)species assignment (Tables 1 and 2). Aligned and trimmed sequences were between $393 \mathrm{bp}$ and $573 \mathrm{bp}$ in length 
Table 1 Key characteristics of the SBSEC-MLST scheme for the overall SBSEC, Sii and S. lutetiensis

\begin{tabular}{|c|c|c|c|c|c|c|c|c|c|c|c|c|c|c|}
\hline \multirow{3}{*}{\multicolumn{2}{|c|}{ Index of association ${ }^{1}$}} & \multirow{4}{*}{$\begin{array}{l}I_{A} \\
I_{A}^{S} \\
A^{3}[b p]\end{array}$} & \multicolumn{4}{|c|}{$\operatorname{SBSEC}(n=74)^{2}$} & \multicolumn{4}{|c|}{ Sii $(n=39)$} & \multicolumn{4}{|c|}{ S. lutetiensis $(n=8)$} \\
\hline & & & \multirow{2}{*}{\multicolumn{4}{|c|}{$\begin{array}{l}.132 \\
0.349\end{array}$}} & \multirow{2}{*}{\multicolumn{4}{|c|}{$\begin{array}{l}2.079 \\
0.231\end{array}$}} & \multirow{2}{*}{\multicolumn{4}{|c|}{$\begin{array}{l}2.422 \\
0.269\end{array}$}} \\
\hline & & & & & & & & & & & & & & \\
\hline Gene & Gene product & & $\mathrm{A}^{3}[\mathrm{no}]$ & $d_{N} / d_{S}$ & $\mathrm{pms}^{4}[\mathrm{No}(\%)]$ & $\mathrm{SID}(95 \% \mathrm{Cl})^{5}$ & $\mathrm{~A}[\mathrm{no}]$ & $d_{N} / d_{S}$ & pms [No (\%)] & SID & $\mathrm{A}[\mathrm{no}]$ & $d_{N} / d_{S}$ & pms [No (\%)] & SID \\
\hline$d d l A$ & $\begin{array}{l}\text { D-alanine-D-alanine } \\
\text { ligase }\end{array}$ & 489 & 28 & 0.079 & $143(29.2)$ & $0.905(0.867-0.943)$ & 5 & 0.171 & $5(1)$ & $0.704(0.648-0.761)$ & 6 & 0.123 & $18(3.7)$ & $0.929(0.840-1.017)$ \\
\hline$g k i$ & glucokinase & 438 & 27 & 0.059 & $119(27.2)$ & $0.901(0.858-0.944)$ & 5 & 0.144 & $5(1.1)$ & $0.668(0.584-0.752)$ & 5 & 0.072 & $21(4.8)$ & $0.893(0.722-1.064)$ \\
\hline$g \ln A$ & $\begin{array}{l}\text { glutamine } \\
\text { synthetase }\end{array}$ & 396 & 21 & 0.039 & $59(14.9)$ & $0.906(0.878-0.934)$ & 7 & 0.163 & $8(2)$ & $0.745(0.688-0.802)$ & 6 & 0.064 & $10(2.5)$ & $0.929(0.806-1.052)$ \\
\hline muts & $\begin{array}{l}\text { DNA mismatch } \\
\text { repair ATPase }\end{array}$ & 552 & 30 & 0.028 & $172(31.2)$ & $0.926(0.894-0.959)$ & 5 & 0.066 & $4(0.7)$ & $0.752(0.688-0.815)$ & 5 & 0.055 & $39(7.1)$ & $0.857(0.704-1.010)$ \\
\hline mutS2 & $\begin{array}{l}\text { mismatch repair } \\
\text { ATPase }\end{array}$ & 495 & 36 & 0.030 & $159(32.1)$ & $0.93(0.890-0.969)$ & 10 & 0.263 & $10(2)$ & $0.762(0.656-0.869)$ & 5 & 0.022 & $44(8.9)$ & $0.857(0.704-1.010)$ \\
\hline phes & $\begin{array}{l}\text { phenylalanyl tRNA } \\
\text { synthetase }\end{array}$ & 480 & 28 & 0.026 & $110(22.9)$ & $0.923(0.889-0.957)$ & 10 & 0.009 & $51(10.6)$ & $0.776(0.680-0.872)$ & 4 & 0.015 & $18(3.8)$ & $0.643(0.301-0.985)$ \\
\hline pros & $\begin{array}{l}\text { prolyl tRNA } \\
\text { synthetase }\end{array}$ & 417 & 28 & 0.059 & $128(30.7)$ & $0.92(0.887-0.953)$ & 7 & 0.353 & $7(1.7)$ & $0.756(0.678-0.833)$ & 5 & 0.106 & $18(4.3)$ & $0.786(0.521-1.051)$ \\
\hline pyrE & $\begin{array}{l}\text { orotate phosphoribosyl } \\
\text { transferase }\end{array}$ & 393 & 36 & 0.022 & $97(24.7)$ & $0.972(0.961-0.983)$ & 16 & 0.061 & $22(5.6)$ & $0.927(0.894-0.960)$ & 5 & 0.013 & $22(5.6)$ & $0.857(0.704-1.010)$ \\
\hline thrs & $\begin{array}{l}\text { threonyl tRNA } \\
\text { synthetase }\end{array}$ & 573 & 31 & 0.074 & $168(29.3)$ & $0.957(0.941-0.974)$ & 11 & 0.105 & 99 (17.3) & $0.883(0.842-0.924)$ & 5 & 0.061 & $27(4.7)$ & $0.857(0.704-1.010)$ \\
\hline tpiA & $\begin{array}{l}\text { triosephosphate } \\
\text { isomerase }\end{array}$ & 408 & 17 & 0.119 & $36(8.8)$ & $0.894(0.862-0.927)$ & 4 & 0.152 & $3(0.7)$ & $0.687(0.637-0.737)$ & 5 & 0.056 & $12(2.9)$ & $0.893(0.816-0.969)$ \\
\hline Mean ( & $95 \%$ Cl) & & & & & $0.924(0.874-0.973)$ & & & & $0.766(0.602-0.93)$ & & & & $0.85(0.682-1.018)$ \\
\hline
\end{tabular}

${ }^{1}$ Index of association based on one strain per ST: IA: calculated using classical Maynard Smith approach, IA: standardized according to Haubold

${ }^{2}$ SBSEC: includes also 3 S. gallolyticus subsp. pasteurianus and 1 S. alactolyticus strains not listed separately

${ }^{3} A$ allele

${ }^{4} \mathrm{Pms}$ polymorphic sites

${ }^{5}$ SID (95 \% Cl): Simpson's index of diversity with $95 \%$ confidence interval (CI) calculated from SID+/- 2*Standard deviation

${ }^{6}$ no $d_{N} / d_{S}$ calculation due to limited allele numbers and differences

Values were calculated for the entire SBSEC and individual (sub)species, including all 10 target genes and Simpson's index of diversity (SID) as an indication for the differentiation power among strains 
Table 2 Key characteristics of the SBSEC-MLST scheme for S. equinus, Sgg and Sgm

\begin{tabular}{|c|c|c|c|c|c|c|c|c|c|c|c|c|c|c|}
\hline \multirow{3}{*}{\multicolumn{2}{|c|}{ Index of association ${ }^{1}$}} & \multirow{4}{*}{$\begin{array}{l}I_{A} \\
I_{A}^{S} \\
A^{3}[b p]\end{array}$} & \multicolumn{4}{|c|}{ S. equinus $(n=10)$} & \multicolumn{4}{|c|}{$\operatorname{Sgg}(n=6)$} & \multicolumn{4}{|c|}{$\operatorname{Sgm}(n=7)$} \\
\hline & & & \multicolumn{4}{|l|}{2.092} & \multicolumn{4}{|l|}{2.093} & \multicolumn{4}{|l|}{0.329} \\
\hline & & & \multicolumn{4}{|l|}{0.232} & \multicolumn{4}{|l|}{0.233} & \multicolumn{4}{|l|}{0.037} \\
\hline Gene & Gene product & & $\bar{A}[\mathrm{no}]$ & $d_{N} / d_{S}$ & pms [No (\%)] & SID & A [no] & $d_{N} / d_{S}$ & pms [No (\%)] & SID & $\mathrm{A}[\mathrm{no}]$ & $d_{N} / d_{S}$ & pms [No (\%)] & SID \\
\hline$d d l A$ & $\begin{array}{l}\text { D-alanine-D-alanine } \\
\text { ligase }\end{array}$ & 489 & 8 & 0.093 & $52(10.6)$ & $0.956(0.894-1.018)$ & 6 & 0.098 & $8(1.6)$ & $1.000\left(\mathrm{NaN}^{7}-\mathrm{NaN}\right)$ & 2 & 2.070 & $4(0.8)$ & $0.286(-0.092-0.664)$ \\
\hline$g k i$ & glucokinase & 438 & 8 & 0.061 & $32(7.3)$ & $0.956(0.894-1.018)$ & 3 & 0.000 & $6(1.4)$ & $0.600(0.215-0.985)$ & 3 & $-{ }^{6}$ & $6(1.4)$ & $0.714(0.563-0.865)$ \\
\hline$g \ln A$ & glutamine synthetase & 396 & 2 & 0.000 & $1(0.3)$ & $0.200(-0.104-0.504)$ & 2 & 0.000 & $3(0.8)$ & $0.600(0.600-0.600)$ & 1 & $-{ }^{6}$ & $0(0)$ & $0(0.000-0.000)$ \\
\hline muts & $\begin{array}{l}\text { DNA mismatch } \\
\text { repair ATPase }\end{array}$ & 552 & 10 & 0.015 & $43(7.8)$ & $1.000\left(\mathrm{NaN}^{7}-\mathrm{NaN}\right)$ & 3 & 0.037 & $17(3.1)$ & $0.600(0.215-0.985)$ & 4 & 0.123 & $6(1.1)$ & $0.810(0.630-0.989)$ \\
\hline mutS2 & $\begin{array}{l}\text { mismatch repair } \\
\text { ATPase }\end{array}$ & 495 & 10 & 0.010 & $28(5.7)$ & $1.000\left(\mathrm{NaN}^{7}-\mathrm{NaN}\right)$ & 5 & 0.017 & $13(2.6)$ & $0.933(0.805-1.062)$ & 2 & 0.000 & $2(0.4)$ & $0.571(0.465-0.678)$ \\
\hline phes & $\begin{array}{l}\text { phenylalanyl tRNA } \\
\text { synthetase }\end{array}$ & 480 & 8 & 0.075 & $14(2.9)$ & $0.956(0.894-1.018)$ & 3 & 0.000 & $11(2.3)$ & $0.600(0.215-0.985)$ & 2 & $-{ }^{6}$ & $1(0.2)$ & $0.286(-0.092-0.664)$ \\
\hline pros & prolyl tRNA synthetase & 417 & 9 & 0.046 & $59(14.1)$ & $0.978(0.927-1.028)$ & 4 & 0.000 & $5(1.2)$ & $0.800(0.528-1.072)$ & 1 & $-{ }^{6}$ & $0(0)$ & $0.000(0.000-0.000)$ \\
\hline pyrE & $\begin{array}{l}\text { orotate phosphoribosyl } \\
\text { transferase }\end{array}$ & 393 & 7 & 0.040 & $21(5.3)$ & $0.933(0.871-0.995)$ & 5 & 0.000 & $4(1)$ & $0.933(0.805-1.062)$ & 3 & 0.042 & $16(4.1)$ & $0.762(0.655-0.869)$ \\
\hline thrs & $\begin{array}{l}\text { threonyl tRNA } \\
\text { synthetase }\end{array}$ & 573 & 7 & 0.000 & $17(3)$ & $0.933(0.871-0.995)$ & 4 & 0.032 & $18(3.1)$ & $0.800(0.528-1.072)$ & 2 & 0.096 & $87(15.2)$ & $0.286(-0.092-0.664)$ \\
\hline tpiA & $\begin{array}{l}\text { triosephosphate } \\
\text { isomerase }\end{array}$ & 408 & 3 & 0.049 & $7(1.7)$ & $0.511(0.200-0.822)$ & 2 & 0.000 & $1(0.2)$ & $0.533(0.277-0.790)$ & 2 & 0.000 & $1(0.2)$ & $0.476(0.183-0.769)$ \\
\hline \multicolumn{2}{|c|}{ Mean $(95 \%$ Cl) } & & & & & $0.842(0.307-1.378)$ & & & & $0.74(0.393-1.087)$ & & & & $0.419(-0.173-1.011)$ \\
\hline
\end{tabular}

${ }^{1}$ Index of association based on one strain per ST: $\mathrm{I}_{\mathrm{A}}$ : calculated using classical Maynard Smith approach, $I_{\mathrm{A}}^{\mathrm{S}}$ : standardized according to Haubold

${ }^{2}$ SBSEC: includes also 3 S. gallolyticus subsp. pasteurianus and $1 \mathrm{~S}$. alactolyticus strains not listed separately

${ }^{3} A$ allele

Pms polymorphic sites

${ }^{5} \mathrm{SID}(95 \% \mathrm{Cl})$ : Simpson's index of diversity with $95 \%$ confidence interval (Cl) calculated from SID+/- $2 *$ Standard deviation

${ }^{6}$ no $d_{N} / d_{S}$ calculation due to limited allele numbers and differences

${ }^{7} \mathrm{NaN}$ : maximum diversity, no Cl calculcated. Values were calculated for the entire SBSEC and individual (sub)species, including all 10 target genes and Simpson's index of diversity (SID) as an indication for the

differentiation power among strains 
(Tables 1 and 2). In total, 66 sequence types (ST) were defined for the 74 strains analyzed. The number of alleles ranged from 17 for tpiA to 36 for pyrE and mutS2, while the number of polymorphic sites (PMS) ranged from 36 for tpiA to 172 for mutS (Tables 1 and 2). The number of alleles and PMS were lower for individual species of the SBSEC (Tables 1 and 2). tpiA showed the highest degree of conservation whereas mutS2 and pyrE displayed the highest variability, which was also reflected in the total number of alleles defined.

SplitsTree analysis of each individual locus provided network-like structures for all ten loci [Additional file 7]. Least-square tree fitting resulted in values $>99.899$ for all trees. Within each SplitsTree network, separate clusters were distinguishable for the $S$. gallolyticus and $S$. infantarius branch, with $S$. alactolyticus as the most distant species.

The index of association $\left(\mathrm{I}_{\mathrm{A}}\right)$ and its standardized version $\left(\mathrm{I}_{\mathrm{A}}^{\mathrm{S}}\right)$ for the overall SBSEC were 3.132 and 0.349 , respectively (Tables 1 and 2 ). $\mathrm{I}_{\mathrm{A}}^{\mathrm{S}}$ values calculated for individual groups were 0.037 (Sgm), 0.231 (Sii), 0.232 (S. equinus), 0.233 (Sgg), 0.286 (S. infantarius branch), and 0.437 (S. gallolyticus branch), while Sgp comprised too few strains for calculation. Except for Sgm, all other groups including SBSEC displayed significant linkage disequilibrium, suggesting recombinatory evolution. Simpson's Index of Diversity (SID), which indicates the discrimination power of the method, was 0.924 (95\% CI: 0.874-0.973) for the overall SBSEC approach and 0.766 (0.602-0.93) for Sii (Tables 1 and 2).

\section{Definition of clonal complexes}

Clonal complexes (CC) are an important classification tool for MLST schemes. CCs were defined for strains that share 7 out of 10 loci using eBURST V3, and these were depicted in a profile-based neighbor-joining tree [Additional file 8]. A total of $10 \mathrm{CCs}$ were determined, which grouped 42 strains and left 32 singletons. CC1 and CC7 were both composed of West African dairy strains, whereas Kenyan and Somali strains were both grouped in CC4 and CC8 [Additional file 8]. CC2 represented the main human pathogen strain cluster that delineated in close relationship with Ivorian dairy cluster CC7. Small CCs comprising two strains each were found for Sgp (CC9) and S. lutetiensis (CC10). CC3 comprised most of the dairy Sgm strains from Africa and Greece, suggesting close relationships among strains of this subspecies. S. bovis (CC6) and S. equinus (CC5) cannot yet be considered as real CCs, as each $\mathrm{CC}$ contained only two versions of the corresponding type strain obtained from different sources. The number of strains did not allow the definition of CCs for $S g g$ or the prediction of a founding strain per CC. The defined CCs 1-10 suggest clear regional relationships among Sii dairy strains $(C C 1$,
CC4 and CC8) and even across continents (CC3), but also pathogenic relationships concentrated in $\mathrm{CC} 2$.

\section{MLST-based phylogeny of SBSEC and individual (sub)species groups}

The SBSEC MLST scheme provides the first detailed overview of all (sub)species within the SBSEC (Fig. 1). All branches 1-18 were numbered sequentially for ease of comparison using the CC definition of 7 or more identical alleles out of 10 .

Primary differentiation established an S. gallolyticus clade (branches 14-17) and an S. equinus/S. lutetiensis/ Sii clade (branches 1-13). Within each clade, speciesspecific clades were delineated. The $S$. equinus clade (13) harbored both the S. equinus and S. bovis type strains that originally defined SBSEC (Fig. 1). S. equinus/S.bovis strains were distributed between a ruminal/human clade (branches 13.2-13.8) and an equine branch (13.1). $S$. equinus JB1, a ruminant isolate, delineated a separate branch (11) with closer association with the S. lutetiensis clade than the major $S$. equinus branch, suggesting reclassification of this strain based on MLST analysis. The S. lutetiensis clade reflected a major division between human clade (branches 12.2-12.6) and a potential side branch (12.1) comprising an animal strain (Fig. 1). The human clade was further divided into human blood and fecal isolates.

The S. gallolyticus clade showed subdivision into a clade comprising $S g g$ and $S g p$, and a separate clade of $S g m$ (Fig. 1). Within the $S g g / S g p$ clade, separate clades were delineated for human pathogenic strains of $S g g$ (branches 17.2-17.3) and Sgp (branches 16.1-16.3). Animal commensal strains seemed more heterogeneous, forming two separate branches, one for the Sgg type strain DSM16831 ${ }^{\mathrm{T}}$ (branch 17.1) and one even further related for the calf isolate LMG17958 (branch 15), indicating different lineages of commensal and pathogenic origins. Among the Sgm strains, the divisions between Greek (branch 14.5), East African (branch 14.4) and West African (branches 14.1-14.3) strains were fully reflected, suggesting a main African lineage that was further differentiated into East and West African lineages.

The Sii clade was analyzed in more detail [Additional file 9]. Several dairy and human clades were delineated, suggesting a general trend of different lineages. Strains of human clinical cases were concentrated in only two specific clades comprising branches 6.4-6.6 and branch 9 regardless of geographic origin. The majority of dairy strains were found in two dairy clades comprising (i) East African dairy isolates (branches 1, 2, 3 and 4) and (ii) West African and Asian dairy isolates (branches 7 and 8), suggesting different lineages within the main dairy lineage of Sii. East African dairy strains formed a single clade subdivided into two main clades of dairy 


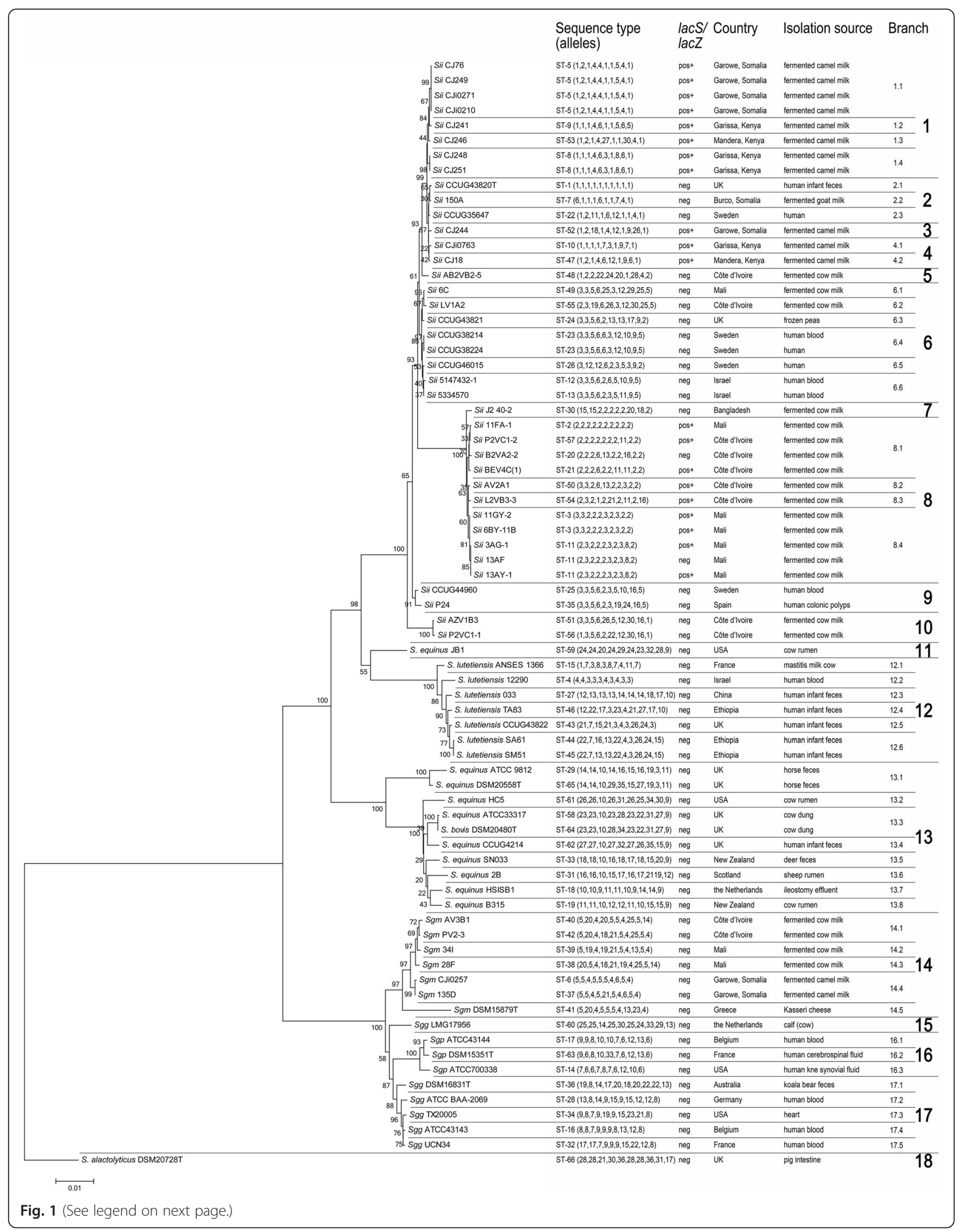


(See figure on previous page.)

Fig. 1 Sequence-based phylogenetic MLST tree of the SBSEC. The MLST tree comprised commensal animal and human strains, human pathogenic strains and food-derived strains of all SBSEC species. The tree was calculated from the concatenated sequences of the 10 MLST loci of each strain using the neighbor joining algorithm and 1000 bootstrap replications. The tree was rooted to S. alactolyticus DSM20728 ${ }^{\top}$. Corresponding STs, alleles and prevalence of dairy adaptation marker genes (lacS/lacZ), origin and isolation source are indicated. Branches were defined and numbered according to the clonal complex specifications

isolates only (branch 1) and mixed human and dairy isolates comprising the Sii type strain (branches 2-4). The majority of West African and the Asian dairy isolates were grouped in a single dairy clade comprising clades 7 and 8 . The delineation of clades 7 and 8 was directly linked to thrS alleles 2,8 and 18 featuring highest sequence identities of 99.1-99.3\% to S. thermophilus instead of other Sii or SBSEC members as for the other 9 alleles. However, West African dairy strains were more heterogeneous than those of East Africa [Additional file 9], and also featured in addition to clade 8 several shared or related clades with human blood isolates (branches 6 and 10) and East African dairy isolates (branch 5).

\section{Prevalence of lacS/lacZ genes as marker genes for dairy adaptation}

The prevalence of $S$. thermophilus-like lacS/lacZ genes was assessed as marker genes for dairy adaptations among all SBSEC, including Sii strains, using specific PCR assays and previously obtained data [29, 31]. Only Sii strains were found to harbor lacS/lacZ, with highest prevalence among the major dairy branches 1 (8/8), 3 (1/1), 4 (2/2) and 8 (9/12) (Fig. 1 and [Additional file 9]). In contrast, dairy strains more closely related to human strains, such as Sii 150A (branch 2) and the four West African dairy strains found in branches 6 and 10, did not harbor the lacS/lacZ genes.

\section{Resistance to simulated gastric juice (SGJ)}

The resistance of SBSEC strains $(n=59)$ to SGJ was tested in SGJ at pH 3.0 or $\mathrm{pH} 2.5$ and $\mathrm{PBS}$ at $\mathrm{pH} 6.0$ as control ([Additional files 10, 11 and 12]). All differences in this section were tested for significance at $p<0.05$ unless mentioned otherwise. Generally, relative cell survival was significantly different for the three conditions pH $2.5\left(-\log 5.2 \pm 1.1 \mathrm{CFU} \mathrm{mL}^{-1}\right), \mathrm{pH} 3.0(-\log 2.7 \pm$ 1.4 CFU mL $\left.\mathrm{mL}^{-1}\right)$ and PBS pH $6.0(-\log 1.2 \pm 0.4$ CFU mL ${ }^{-1}$ ) over $15 \mathrm{~min}$. Significantly different survival was also observed among strains at $\mathrm{pH} 2.5$ or $\mathrm{pH} 3.0(p<0.05)$ whereas no significant difference was observed among the strains tested under control conditions of PBS pH6.0 $(p>0.05)$ ([Additional files 10, 11 and 12]). Significantly different survival rates were determined between dairy Sii clades 1, 4 and 8 featuring higher survival compared to Sii commensal clade 2 and predominantly blood isolate clade 6, S. lutetiensis clade 12, S. gallolyticus clades
16 and 17 as well as S. alactolyticus branch 18 ([Additional files 10 and 12]).

Survival rates were significantly dependent on time-pH combinations. Conditions of $\mathrm{pH} 2.5$ yielded low survival rates, often below detection limit after $15 \mathrm{~min}$ ([Additional file 10]). This strong inhibition resulted in a few significant differences between strains and MLST branches with the exception of outliers in clade 8 and branch 12.2. Significantly highest relative survival in comparison to all other strains was determined for the four West African dairy Sii strains 6BY-11B, 13AF, 12AY-1 and P2VC1-2, clustered in MLST branches 8.1 and 8.4 as well as the human blood isolate S. lutetiensis 12290 (branch 12.2) and all S. thermophilus strains ([Additional file 10]). Significantly higher relative survival was therefore determined for West African (branches 8.1 and 8.4) compared to East African Sii strains in branches 1 and 2. No significant correlation was observed between lacS/lacZ prevalence, habitat and relative survival under the conditions tested (data not shown).

\section{Adhesion to extracellular matrix proteins}

Adhesion of SBSEC strains to various ECMs was investigated to estimate their interaction with cell surfaces of the GI tract and blood vessels. Due to heavy tailed distributed values, all adhesion values were normalized and analyzed using a median-based calculation (Fig. 2).

Lb. plantarum WCFS1 and Lb. reuteri DSM $20016^{\mathrm{T}}$ were used as positive adhesion controls showing significant adhesion towards fibronectin, fibrinogen, collagen I and mucin type II that are known factors contributing to their persistence in the human GI tract. As expected, $L b$. plantarum NZ7114, the sortase knockout mutant of WCSF1 depleted of its adhering surface proteins, showed no adhesion and served as negative adhesion control. Adhesion values obtained at experimental conditions of $\mathrm{pH} 5.5$ showed better reproducibility in contrast to those values obtained at $\mathrm{pH} 7.5$ and were therefore chosen for analysis.

Adhesion characteristics were separated by MLST clustering and isolate origin. Generally, adhesion was most prevalent to the two ECMs collagen I and mucin type II, with 22.6 and $24.5 \%$ of SBSEC isolates showing adhesion (total $n=53$ ), respectively, followed by adhesion to fibronectin, fibrinogen and collagen IV by $18.9 \%$ of SBSEC isolates. 


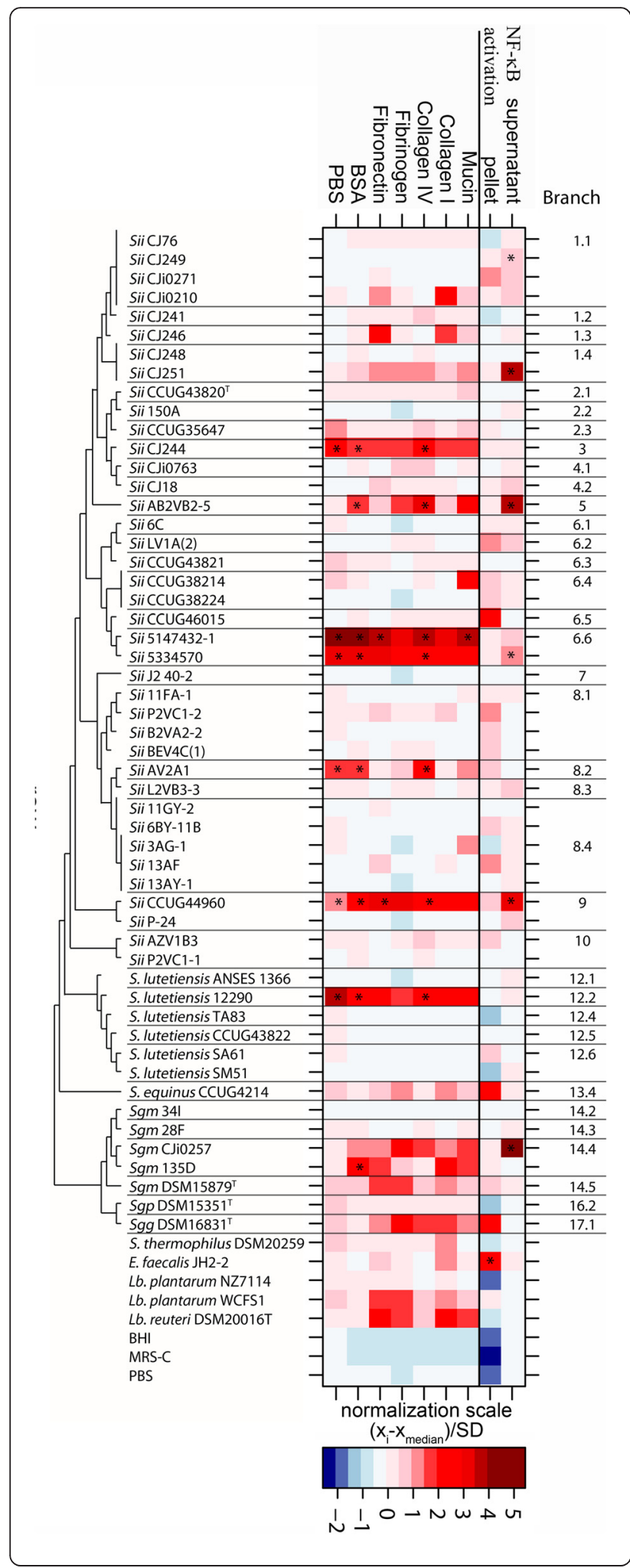

Fig. 2 Analysis of the adhesion ability of SBSEC members to extracellular matrix proteins and activation of the NF-kB signaling pathway. Adhesion and NF-kB activation values of individual strains displayed in a heat map. The phylogenetic tree is based on the MLST-tree but not drawn to scale for better visualization. Adhesion measurements were normalized for each strain based on the adhesion median of all strains. Values larger than 1 SD from the normalized 0 adhesion were considered to be adherent. Outliers were marked using an asterix*

Among human Sii, adhesion to mucin type II and unspecific adhesion was observed for $44.4 \%$ and adhesion to all remaining ECMs for $33 \%$ of human Sii strains ( $n$ =9). Among these human strains, comparison of blood isolates $(n=4,5147432-1,5334570$, CCUG38214 and CCUG44960) and potentially commensal isolates $(n=5$, CCUG35647, CCUG38224, CCUG43820 ${ }^{\mathrm{T}}$, CCUG46015 and P-24) showed that significant adhesion was exclusively present among Sii blood isolates comprised mainly in branches 6.6 and 9. Human fecal isolate Sii CCUG $43820^{\mathrm{T}}$ featured no significant adhesion abilities to fibronectin, fibrinogen or collagen I and only weak adhesion to collagen IV and mucin type II. Similarly, $S$. lutetiensis blood isolate 12290 (branch 12.2) displayed significant wide range adhesion abilities whereas human fecal isolates of S. lutetiensis (branches 12.3-12.6) displayed no significant adhesion abilities, suggesting low prerequisite or other mechanisms contributing to the persistence of these possibly commensal Sii and S. lutetiensis strains in the human GI tract (Fig. 2).

Similarly, dairy Sii $(n=29$, clades $1-5,6.1,6.2,8$ and 10) generally had a low prevalence of adhesion abilities to the ECMs tested and those dairy Sii isolates showing adhesion, featured mainly adhesion to collagen IV and mucin type II detected in 13.8 and $17.2 \%$ of strains, respectively, with the exception of CJi0210, CJ246, CJ244 and AB2VB2-5 showing also adhesion to collagen I or mucin type II. Clustered according to MLST and geography, West African dairy Sii of MLST branches 8.1, 8.4 and 10 displayed low adhesion abilities to the ECMs tested. Adhesion was more prevalent among East African dairy Sii strains with significant adhesion to at least one ECM for strains CJi0210, CJ246, CJ244 and CJ251 as well as West African dairy Sii strain AB2VB25, which all share the same MLST clade 1-5 (Fig. 2). The significantly adherent West African dairy strain Sii AV2A1 was the exception to cluster with the otherwise low-adherent strains of the West African main dairy clade 8 (Fig. 2).

Among the S. gallolyticus clade 14-18, high adhesion abilities towards collagen I, IV and fibrinogen was observed. Dairy Sgm branches of East Africa (branches 14.2-14.4) and Greece (branch 14.5) showed adhesion towards mucin type II and fibronectin. In contrast, Sgp 
(branch 16.2) did not display any significant adhesion abilities allowing clear separation by MLST clustering from Sgg (branch 17.1).

\section{Determination of immune stimulatory potential by NF-KB activation}

Activation of the transcription factor NF-KB was used as marker for the immune stimulation of the SBSEC strains studied (Fig. 2) using the THP1-Blue reporter cell line that expresses all TLRs that detect bacterial motifs in the intestine. NF-KB activation was generally low for the strain panel tested with significantly higher values obtained for cell pellets (mean 0.41, $95 \% \mathrm{CI}=0.48-0.55$ ) in contrast to cell-free supernatants (mean 0.05, $95 \% \mathrm{CI}$ $=0.12-0.15$ ). Cell pellets, significant inflammation was detected only for individual strains such as Sii CCUG46015 (branch 6.5), S. equinus CCUG4214 (branch 13.4) and Sgg DSM $16831^{\mathrm{T}}$ (branch 17.1). The majority of dairy isolates and also human commensal and blood isolates did not significantly activate NF-KB, particularly in comparison to control strain E. faecalis JH2-2. Among cell-free supernatants, highest NF-KB activation was measured for dairy isolates Sii AB2VB2-5 (branch 5), Sii CJ251 (branch 1.4) and Sgm CJi0257 (branch 14.4), as well as human blood isolates Sii 5334570 (branch 6.6) and Sii CCUG44960 (branch 9), displayed significant NF-KB activation. Again, no significant NF-KB activation was detected among supernatants of other human commensal strains of $S$. lutetiensis, Sii and even pathogenic $S$. lutetiensis, Sii, Sgg and Sgp.

\section{Discussion}

The SBSEC is a highly diverse group of bacteria colonizing multiple habitats such as food, human and animal GI tracts. Although the $16 \mathrm{~S}$ rRNA gene sequence provides sufficient power to differentiate the main branches of S. gallolyticus, S. infantarius and S. alactolyticus, differentiation at subspecies level requires sequencing of additional genes such as groEL $[29,32]$. We showed that groEL provided stringent sequence data and discrimination power for SBSEC subspecies identification. Interestingly, Sii J2 40-2 seems to be an exception, 16S rRNA gene sequence suggested an $S$. infantarius branch member while groEL indicates highest similarity with Sgm; however, the identity in the SBSEC MLST scheme was confirmed to be Sii. The ongoing horizontal gene transfer (HGT) among streptococci and SBSEC [18, 19] in combination with natural competence [20] may have changed even genes considered as housekeeping genes. Further indications for HGT between dairy Sii and $S$. thermophilus were observed among thrS alleles of strains comprised in MLST clades 7 and 8 representing Asian dairy strain Sii J2 40-2 and the major West African clade. Most strains in clade 8 harbor lacS and lacZ which serve as marker genes for $S$. thermophilus-like dairy adaptation. In combination with the thrS alleles present, this suggests a common ancestor for clades 7 and 8 that underwent multiple HGT with $S$. thermophilus. Ultimately, these observations of HGT and natural competence support the need for a multi gene approach such as MLST for SBSEC (sub)species to ensure accurate identification as well as inter- and intraspecies phylogenetics.

The SBSEC MLST scheme developed in this study provides the first multi-gene-based comparison across the entire SBSEC. In contrast to previous Sgg MLST schemes $[15,16]$, this scheme provides a tool for clustering all currently described SBSEC species and subspecies from human, animal and food sources. The SID of $0.740-0.924$ is within the range and confidence interval of that of the Sgg MLST (0.84, $95 \%$ CI 0.735-0.931) [15]. Therefore, our novel SBSEC MLST assay provides equally high differentiation power as the $S g g$-specific assays without the restriction of being limited to a single species but instead being applicable to all (sub)species of the SBSEC. Furthermore, extraction and phylogenetic comparison of MLST alleles from whole genome sequences as performed for several strains in this study ensure the application of this SBSEC MLST scheme also in combination with next generation sequencing of bacterial genomes as data source instead of traditional Sanger sequencing.

The SBSEC MLST scheme provided highly comparable phylogenetic tree delineation for $S g g$ as those obtained via the $S g g$-specific MLST scheme. $\mathrm{d}_{\mathrm{N}} / \mathrm{d}_{\mathrm{S}}$ ratios of all loci in the SBSEC MLST scheme were $<1$ and comparable to those of the two $S g g$-specific schemes $[15,16]$. Number and percentage of PMS of most loci were in the range of Dumke et al. (2014) at 2.23-7.40\% and Shibata et al. (2014) at 6.4-11.1 \%. The $\mathrm{I}_{\mathrm{A}}$ of $2.079-2.271$ for individual species was slightly lower than the $\mathrm{I}_{\mathrm{A}}$ of 2.4 determined by Dumke et al. (2014) whereas Shibata et al. (2014) did not provide a value for $\mathrm{I}_{\mathrm{A}}$. The $\mathrm{I}_{\mathrm{A}}$ values for the overall SBSEC, S. equinus, Sgg, Sii and S. lutetiensis indicated significant linkage disequilibrium between the 10 selected loci as previously observed for the loci set of Sgg [15]. Linkage disequilibrium is the effect of nonrandom association of the selected alleles in an MLST scheme [57], which indicates that recombination was a factor in the evolution of the SBSEC as seen also by network-like structures in SplitsTree analyses [Additional file 7] [37, 41]. Sgm was the only subspecies where linkage disequilibrium was not detected. Sgm also displayed the lowest genetic diversity despite the analysis of Greek, Somali, Ivorian and Mali strains, suggesting that Sgm strains from these different origins are highly related. This could support the theory that $S g m$ is actually a subspecies of dairy origin within the SBSEC [18], enabled through clear delineation from other SBSEC members in this 
MLST scheme. Genome sequencing of Sgm strains will be required to further assess their evolution in relation to the presence of putative Sgm dairy adaptation markers such as duplicated lacG2 described for Sgm ACA-DC 198 and decayed or active virulence factors [58].

Sgg and S. lutetiensis showed a clear differentiation between presumptive human commensal lineages and those of infectious nature isolated from feces, blood or heart samples of humans and animals. In particular, commensal strains such as koala bear isolate $\operatorname{Sgg}$ DSM $16831^{\mathrm{T}}$ and calf isolate Sgg LMG17956 were clearly distinct from human pathogenic lineages, suggesting the existence of potentially commensal and pathogenic lineages among many SBSEC species. This requires evaluation in a One Health approach, encompassing animal and human health, food, the zoonotic potential of SBSEC members and their status as pathobionts [21, 59].

The subspecies Sii that originated from human and animal-derived food sources had the highest representation in this MLST assay. Clear regional differentiation was observed for the majority of East and West African dairy strains. Differentiation by host and source was observed for most human and dairy strains, suggesting different lineages depending on fecal or blood origin. The MLST phylogeny suggests that human fecal and especially blood isolates cluster by isolation source (feces or blood), and not by geographical origin in contrast to most dairy strains. This possibly reflects different adaptation and risk levels.

Dairy strains clustered in distinct lineages featuring a prominent West African and Asian main branch and an East African branch. The main lineage of East African dairy strains displayed remarkable conservation in contrast to the higher diversity among West African strains and especially those collected in Côte d'Ivoire. The regions of Mandera and Garissa in Kenya share a common cultural background with Somalia. Large Somali populations are represented in both Kenyan regions, with a long tradition in livestock trading, mobile pastoral lifestyle and migration across borders [60, 61], possibly explaining the spreading of similar strain lineages. Certain lineages among the West African dairy Sii without the marker genes lacS/lacZ clustered separately from the main dairy lineages and closer to human fecal and pathogenic isolates, suggesting the existence of overlapping lineages of Sii or contamination of foods by fecal material. This raises concerns about potential health risks of these strain lineages and the origin of these lineages in food.

Exposure of strains to SGJ was used to assess the survival of bacteria in stomach conditions and delivery potential to the colon. Generally, strains of MLST clusters showed similar relative survival being affected by SGJ. However, at pH 3.0 and pH 2.5 several dairy Sii clades and mainly four dairy strains showed significantly higher relative survival than human blood Sii isolates/clades, respectively, suggesting different adaptation to acidic stress in relation to strain origin and MLST clustering.

MLST-based clustering was further used to assess the ability of individual strains to adhere to ECM and activate the NF-KB pathway in correlation with MLST clades and phylogeny. Adherence is an important first step in colonization of the GI tract or damaged body tissues such as heart valves. MLST clusters provided clear differentiation of highly adhesive Sii/S. lutetiensis blood isolates, the $S$. gallolyticus clade, less adhesive East African dairy strains and nearly non-adhesive West African strains, suggesting a generally lower tendency among West African dairy clades and commensal $S$. lutetiensis to adhere to the ECMs tested. The genetic factors contributing to adhesion were so far only related to a specific pilus loci for collagen binding termed pil1, pil2 and pil3 present in the Sgg genomes analyzed [58, 62]. Only pil3 was found in Sii, Sgm and $S g p$, whereas the crucial pil1 factor of Sgg was absent $[19,58]$. Comparative genomics and further functional analyses are needed to determine the responsible factors in highly adhering strains of Sii, S. lutetiensis, Sgm and $S g g$, and possibly identify new virulence factors to enable an in-depth risk assessment for the different SBSEC species in relation to human and animal diseases.

The NF-KB activation by bacteria attaching to the intestinal mucosa plays a central role in immune signaling of the host, particularly in the intestinal tract. For most strains, NF-KB activation was positively correlated with significant adhesion abilities, suggesting health implications and the need for further functional analyses for such strains. Several blood isolates as well as pathogenic Sgp DSM $15351^{\mathrm{T}}$ did not yield significant NF-KB activation, which could enable them to infect the host without inducing a strong immune response [11].

\section{Conclusions}

The overarching MLST scheme for the entire SBSEC provides an epidemiologic and diagnostic tool enabling indepth inter- and intra(sub)species comparisons of all (sub)species within this emerging human and animal pathogenic complex. The MLST scheme based on 10 housekeeping genes allowed delineating all (sub)species within the SBSEC. It enabled division by host and habitat and furthermore possibly pathogenic lineages from commensal and food lineages. This approach will be useful in enhancing taxonomic classifications of human, animal and food isolates as well as their relationships. Our data suggest that the parallel evolution of East and West African dairy lineages is currently in the process of differentiating from the human lineage including genetic exchange with other streptococci. However, enhanced adhesion abilities of certain lineages similar to those of Sgg and the ability to cause inflammation or evade immune response are certainly of concern and require further 
investigations into pathogenicity mechanisms shared among the SBSEC and those unique to only specific (sub)species. This will greatly assist in designing appropriate treatment strategies for patients infected with this emerging pathogenic group depending on MLST clustering. Furthermore, accurately collecting clinically relevant epidemiologic data in relation to transmission, zoonosis, host specificity and identification of virulence mechanisms will greatly contribute to an enhanced risk assessment of pathogenic, commensal and food lineages or the potential role as pathobionts in an overarching One Health approach.

\section{Additional files}

Additional file 1: Title of data: Strains used in this study. Description of data: Strains used in this study. (PDF $239 \mathrm{~kb}$ )

Additional file 2: Title of data: Primers developed and used in this study. Description of data: Primers developed and used in this study for the Sii/SBSEC MLST scheme of housekeeping genes and identification based on groEL, lacS and lacZ genes. (PDF $224 \mathrm{~kb}$ )

Additional file 3: Title of data: MLST candidate loci used in this study. Description of data: All 30 candidate loci which were used in this study were selected from literature and MLST.net (http://www.mlst.net/). Conserved housekeeping genes were selected on the basis of maximal nucleotide divergence for intraspecies differentiation. All loci which are marked with an asterisk were used for the final SBSEC MLST scheme. (PDF $183 \mathrm{~kb}$ )

Additional file 4: Title of data: Sequence identity matrix of 772-bp groEL fragments of SBSEC species. Description of data: Sequence identity matrix of 772-bp groEL fragments of SBSEC species (PDF $92 \mathrm{~kb}$ )

Additional file 5: Title of data: groEL-based phylogenetic tree of SBSEC strains ( $n=74$ ) of this study. Description of data: Phylogenetic tree of all 74 SBSEC strains investigated this study based on neighbor-joining 3 calculation of a 772-bp sequence fragment of the groEL gene. The scale bar below the tree 4 indicates the evolutionary distance using the number of base substitutions per site as units. 5 Species abbreviations: S. infantarius subsp. infantarius (Sii), S. gallolyticus subsp. gallolyticus 6 (Sgg), S, gallolyticus subsp. macedonicus (Sgm), S. gallolyticus subsp. pasteurianus (Sgp). (TIF $1216 \mathrm{~kb}$ )

Additional file 6: Title of data: 165 rRNA gene-based phylogenetic tree of selected SBSEC members. Description of data: Phylogenetic tree of selected SBSEC strains $(n=24)$ of all SBSEC (sub)species based on a 930bp fragment of the $16 \mathrm{~S}$ rRNA gene. Calculations were performed using the neighbor-joining algorithm. The scale bar below the tree indicates the evolutionary distance using the number of base substitutions per site as units. Species abbreviations: S. infantarius subsp. infantarius (Sii), S. gallolyticus subsp. gallolyticus (Sgg), S, gallolyticus subsp. macedonicus (Sgm), S. gallolyticus subsp. pasteurianus (Sgp). (TIF 1425 kb)

Additional file 7: Title of data: SplitsTree visualization of the 10 MLST loci. Description of data: The trees were obtained using the defined allele sequences and calculation by neighbor-joining algorithm. Corresponding

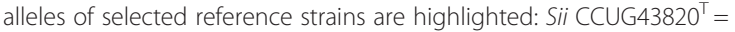
bright green, Sgg DSM16831 ${ }^{\top}=$ red, Sgm DSM15879 ${ }^{\top}=$ ice blue, S. lutetiensis CCUG43822 = yellow, Sgp DSM $15351^{\top}=$ brown, S. bovis DSM20480 $=$ pink, S. equinus DSM20558 ${ }^{\top=}$ dark blue, S. alactolyticus DSM $20728^{\top}=$ orange. (TIF 3424 kb)

Additional file 8: Title of data: Profile-based MLST tree of all species within the SBSEC. Description of data: The strain pool comprises commensal animal and human strains, human pathogenic strains and food-derived strains. The tree was calculated by neighbor joining algorithm using the allele profiles of 10 housekeeping genes. Corresponding sequence types (ST), alleles and prevalence of dairy adaptation marker genes (lacS/lacZ) including origin and isolation source are indicated. Species abbreviations: S. infantarius subsp. infantarius (Sii), S. gallolyticus subsp. gallolyticus (Sgg), S, gallolyticus subsp. macedonicus (Sgm), S. gallolyticus subsp. pasteurianus (Sgp). (TIF $2600 \mathrm{~kb}$ )
Additional file 9: Title of data: Sequence-based phylogenetic MLST tree of S. infantarius subsp. infantarius (Sii). Description of data: The MLST tree comprised commensal animal and human strains, human pathogenic strains and food-derived strains of all SBSEC species. The tree was calculated by neighbor joining algorithm using the concatenated partial sequences of 10 housekeeping genes. Trees were rooted to S. equinus JB1. Corresponding sequence types (ST), alleles and prevalence of dairy adaptation marker genes (lacS/lacZ) including origin and isolation source are indicated. Branches were defined and numbered according to the clonal complex specifications. (TIF $1167 \mathrm{~kb}$ )

Additional file 10: Title of data: Relative survival of SBSEC members under simulated gastric conditions at $\mathrm{pH}$ 2.5. Description of data: Relative survival of SBSEC strains after 5, 10 and 15 min incubation in SGJ at pH 2.5 performed in two biological replications. Relative survival values in $\log _{10}$ CFU mL ${ }^{-1}$ were normalized according to the mean of all measurements of one condition to allow comparison between strains. Positive normalized values indicate relative survival higher than the mean of all strains. Statistical distribution indicators: Median: large black dotted line; Q1 and Q3: small black dotted line; lower and upper outlier fence: large yellow dotted line (only drawn if within the graph range displayed). The phylogenetic tree is based on the MLST-tree but not drawn to scale. (TIF 3894 kb)

Additional file 11: Title of data: Relative survival of SBSEC members under simulated gastric conditions in PBS pH 6.0. Description of data: Relative survival of SBSEC strains at 5, 10 and $15 \mathrm{~min}$ in PBS pH 6.0 performed in 2 biological replications. Input of $0 \log _{10}$ CFU mL $\mathrm{mL}^{-1}$ was used as basis from which relative survival is expressed. Relative survival values were normalized to allow comparison between strains where positive values indicate relative survival higher than the mean of all strains. Statistical distribution indicators: Median: large black dotted line; Q1 and Q3: small black dotted line; lower and upper outlier fence: large yellow dotted line (only drawn if within the graph range displayed). The phylogenetic tree is based on the MLST-tree but not drawn to scale. (TIF $3405 \mathrm{~kb}$ )

Additional file 12: Title of data: Relative survival of SBSEC members under simulated gastric conditions at $\mathrm{pH}$ 3.0. Description of data: Relative survival of SBSEC strains at 5, 10 and $15 \mathrm{~min}$ in in simulated gastric conditions at $\mathrm{pH} 3.0$ performed in 2 biological replications. Input of $0 \log _{10} \mathrm{CFU} \mathrm{mL} \mathrm{m}^{-1}$ was used as basis from which relative survival is expressed. Relative survival values were normalized to allow comparison between strains where positive values indicate relative survival higher than the mean of all strains. Statistical distribution indicators: Median: large black dotted line; Q1 and Q3: small black dotted line; lower and upper outlier fence: large yellow dotted line (only drawn if within the graph range displayed). The phylogenetic tree is based on the MLST-tree but not drawn to scale. (TIF $3007 \mathrm{~kb}$ )

\section{Abbreviations}

CC, clonal complex; CRC, colorectal cancer; ECM, extracellular matrix protein; Gl tract, gastrointestinal tract; $H G T$, horizontal gene transfer; $I_{A}$, index of association; $I_{A}^{S}$, standardized index of association; IE, infective endocarditis; MLST, multi locus sequence typing; PBS, phosphate-buffered saline; PMS, polymorphic sites; SBSEC, Streptococcus bovis/Streptococcus equinus complex; Sgg, Streptococcus gallolyticus subsp. gallolyticus; SGJ, Simulated gastric juice; Sgm, Streptococcus gallolyticus subsp. macedonicus; Sgp, Streptococcus gallolyticus subsp. pasteurianus; Sii, Streptococcus infantarius subsp. infantarius; SID, Simpson's index of diversity; ST, sequence type

\section{Acknowledgments}

The authors greatly acknowledge the SBSEC strains received from Ingolf Nes (Laboratory of Microbial Gene Technology, Dept. Chem. and Biotechnology, Norwegian University of Life Sciences, Norway), Tsilia Lazarovitch (Unit of Infectious Diseases, Assaf Harofeh Medical Center, Israel), Taku Miyamoto (Graduate School of Natural Science and Technology, Okayama University, Okayama, Japan), Rosa del Campo/Beatriz Romero Hernández (Servicio de Microbiología, Hospital Universitario Ramón y Cajal, Madrid, Spain), Marisa Haenni/ Jean-Yves Madec (Anses - Agence nationale de sécurité sanitaire de l'alimentation, de l'environnement et du travail, France). The authors thank Peter Bron and Michiel Kleerebezem (TI Food and Nutrition, Wageningen, The Netherlands) for the gift of Lactobacillus plantarum WCFS1 and Lactobacillus plantarum NZ7114. This study and all authors were funded by the UBS Optimus Foundation, Switzerland and the ERAfrica program theme "New Ideas". 


\section{Funding}

This project was financed by the UBS Optimus Foundation, Switzerland and ERAfrica "New Ideas". The funders had no role in study design, data collection, analysis, interpretation, decision to publish, or preparation of the manuscript. All authors have read and approved the final manuscript.

\section{Availability of data and material}

The data set(s) supporting the results of this article are available in the GenBank and pubmlst.org repositories under accession number ranges [GenBank:KM358381-KM358467] and [GenBank:KP703860-KP703862] and SBSEC MLST database [www.pubmlst.org] [63], respectively.

\section{Authors' contributions}

CJ, DWMK, JA, DB, SV, TS and II performed the experiments to type bacteria isolates, develop and validate the MLST assay and contributed to data analysis and interpretation. JA and TW conducted adhesion and inflammation assays. FK conducted gastric survival assays. JA, TW and FK contributed to data analysis and interpretation of the respective assays. CJ, TW, CL and LM designed and supervised the experiments. CJ, TW, BB, CL, DWMK, WKM and LM performed analyses and interpretation, and wrote and revised the manuscript. All authors read and approved the final manuscript.

\section{Competing interests}

The authors declare that they have no competing interests.

\section{Consent for publication}

Not applicable.

\section{Ethical approval and consent to participate}

Not applicable.

\section{Author details \\ ${ }^{1}$ Laboratory of Food Biotechnology, Institute of Food, Nutrition and Health, ETH Zurich, Schmelzbergstrasse 7, 8092 Zurich, Switzerland. ${ }^{2}$ Centre Suisse de Recherches Scientifiques en Côte d'Ivoire (CSRS), KM 17 route de Dabou, Adiopodoumé Yopougon, Abidjan - 01B.P. 1303, Abidjan, Côte d'Ivoire. ${ }^{3}$ Department of Food Science, Nutrition and Technology, College of Agriculture and Veterinary Sciences, University of Nairobi, P.O. Box 29053, Nairobi, Kenya.}

Received: 10 November 2015 Accepted: 8 June 2016 Published online: 21 June 2016

\section{References}

1. Jans C, Meile L, Lacroix C, Stevens MJA. Genomics, evolution, and molecular epidemiology of the Streptococcus bovis/Streptococcus equinus complex (SBSEC). Infect Genet Evol. 2015;33:419-36.

2. Schlegel L, Grimont F, Ageron E, Grimont PAD, Bouvet A. Reappraisal of the taxonomy of the Streptococcus bovis/Streptococcus equinus complex and related species: description of Streptococcus gallolyticus subsp. gallolyticus subsp. nov., S. gallolyticus subsp. macedonicus subsp. nov. and S. gallolyticus subsp. pasteurianus subsp. nov. Int J Syst Evol Microbiol. 2003;53:631-45.

3. Noble CJ. Carriage of group D streptococci in the human bowel. J Clin Pathol. 1978;31:1182-6

4. Chirouze C, Patry I, Duval X, Baty V, Tattevin P, Aparicio T, et al. Streptococcus bovis/Streptococcus equinus complex fecal carriage, colorectal carcinoma, and infective endocarditis: a new appraisal of a complex connection. Eur J Clin Microbiol Infect Dis. 2013;32:1171-6.

5. Quercia S, Candela M, Giuliani C, Turroni S, Luiselli D, Rampelli S, et al. From lifetime to evolution: timescales of human gut microbiota adaptation. Front Microbiol. 2014:5:587.

6. Boleij A, Tjalsma $H$. The itinerary of Streptococcus gallolyticus infection in patients with colonic malignant disease. Lancet Infect Dis. 2013;13:719-24.

7. Corredoira J, Coira A, Iñiguez I, Pita J, Varela J, Alonso MP. Advanced intestinal cancer associated with Streptococcus infantarius (former S. bovis II/ 1) sepsis. Int J Clin Pract. 2013;67:1358-9.

8. Schoustra SE, Kasase C, Toarta C, Kassen R, Poulain AJ. Microbial community structure of three traditional Zambian fermented products: Mabisi, Chibwantu and Munkoyo. PLoS One. 2013;8:e63948.
9. Tsakalidou E, Zoidou E, Pot B, Wassill L, Ludwig W, Devriese LA, et al. Identification of streptococci from Greek Kasseri cheese and description of Streptococcus macedonicus sp. nov. Int J Syst Bacteriol. 1998;48:519-27.

10. Sillanpää J, Nallapareddy SR, Qin X, Singh KV, Muzny DM, Kovar CL, et al. A collagen-binding adhesin, Acb, and ten other putative MSCRAMM and pilus family proteins of Streptococcus gallolyticus subsp. gallolyticus (Streptococcus bovis group, biotype I). J Bacteriol. 2009;191:6643-53.

11. Boleij A, Muytjens CMJ, Bukhari SI, Cayet N, Glaser P, Hermans PWM, et al. Novel clues on the specific association of Streptococcus gallolyticus subsp gallolyticus with colorectal cancer. J Infect Dis. 2011;203:1101-9.

12. Danne C, Entenza JM, Mallet A, Briandet R, Débarbouillé M, Nato F, et al. Molecular characterization of a Streptococcus gallolyticus genomic island encoding a pilus involved in endocarditis. J Infect Dis. 2011;204:1960-70.

13. Biarc J, Nguyen IS, Pini A, Gossé F, Richert S, Thiersé D, et al. Carcinogenic properties of proteins with pro-inflammatory activity from Streptococcus infantarius (formerly S. bovis). Carcinogenesis. 2004;25:1477-84.

14. Sun B, Karin $M$. The therapeutic value of targeting inflammation in gastrointestinal cancers. Trends Pharmacol Sci. 2014;35:349-57.

15. Dumke J, Hinse D, Vollmer T, Knabbe C, Dreier J. Development and application of a multilocus sequence typing scheme for Streptococcus gallolyticus subsp. gallolyticus. J Clin Microbiol. 2014;52:2472-8.

16. Shibata $Y$, le Tien HT, Nomoto R, Osawa R. Development of a multilocus sequence typing scheme for Streptococcus gallolyticus. Microbiology. 2014; 160:113-22.

17. Corredoira J, Grau I, Garcia-Rodriguez JF, Alonso-Garcia P, Garcia-Pais MJ, Rabuñal R et al. The clinical epidemiology and malignancies associated with Streptococcus bovis biotypes in 506 cases of bloodstream infections. J Infect. 2015; doi:10.1016/j.jinf.2015.05.005.

18. Papadimitriou K, Anastasiou R, Maistrou E, Plakas T, Papandreou NC, Hamodrakas SJ, et al. Acquisition through horizontal gene transfer of plasmid pSMA198 by Streptococcus macedonicus ACA-DC 198 points towards the dairy origin of the species. PLoS One. 2015;10:e0116337.

19. Jans C, Follador R, Hochstrasser M, Lacroix C, Meile L, Stevens MJA. Comparative genome analysis of Streptococcus infantarius subsp. infantarius CJ18, an African fermented camel milk isolate with adaptations to dairy environment. BMC Genomics. 2013;14:200.

20. Morrison DA, Guédon E, Renault P. Competence for natural genetic transformation in the S. bovis group streptococci, S. infantarius and S. macedonicus. J Bacteriol. 2013;195:2612-20.

21. Chow J, Tang H, Mazmanian SK. Pathobionts of the gastrointestinal microbiota and inflammatory disease. Curr Opin Immunol. 2011;23:473-80.

22. Enright MC, Spratt BG. Multilocus sequence typing. Trends Microbiol. 1999;7: 482-7.

23. Lazarovitch T, Shango M, Levine M, Brusovansky R, Akins R, Hayakawa K et al. The relationship between the new taxonomy of Streptococcus bovis and its clonality to colon cancer, endocarditis, and biliary disease. Infection. 2013:41:329-37.

24. Rashid MH, Togo K, Ueda M, Miyamoto T. Identification and characterization of dominant lactic acid bacteria isolated from traditional fermented milk 'Dahi' in Bangladesh. World J Microbiol Biotechnol. 2007;23:125-33.

25. Chuzeville S, Puymège A, Madec JY, Haenni M, Payot S. Characterization of a new CAMP factor carried by an integrative and conjugative element in Streptococcus agalactiae and spreading in streptococci. PLoS One. 2012;7: e48918.

26. Romero B, Morosini M-I, Loza E, Rodríguez-Baños M, Navas E, Cantón R, et al. Reidentification of Streptococcus bovis isolates causing bacteremia according to the new taxonomy criteria: still an issue? J Clin Microbiol. 2011 49:3228-33.

27. Birri DJ, Brede DA, Tessema GT, Nes IF. Bacteriocin production, antibiotic susceptibility and prevalence of haemolytic and gelatinase activity in faecal lactic acid bacteria isolated from healthy Ethiopian infants. Microb Ecol. 2013:65:504-16.

28. Jans C, Bugnard J, Njage PMK, Lacroix C, Meile L. Lactic acid bacteria diversity of African raw and fermented camel milk products reveals a highly competitive, potentially health-threatening predominant microflora. LWTFood Sci Technol. 2012;47:371-9.

29. Jans C, Kaindi DWM, Böck D, Njage PMK, Kouamé-Sina SM, Bonfoh B, et al Prevalence and comparison of Streptococcus infantarius subsp. infantarius and Streptococcus gallolyticus subsp. macedonicus in raw and fermented dairy products from East and West Africa. Int J Food Microbiol. 2013;167: 186-95. 
30. Wullschleger S, Lacroix C, Bonfoh B, Sissoko-Thiam A, Hugenschmidt S, Romanens $\mathrm{E}$, et al. Analysis of lactic acid bacteria communities and their seasonal variations in a spontaneously fermented dairy product (Malian fènè) by applying a cultivation/genotype-based binary model. Int Dairy J. 2013;29:28-35

31. Jans C, Gerber A, Bugnard J, Njage PMK, Lacroix C, Meile L. Novel Streptococcus infantarius subsp. infantarius variants harboring lactose metabolism genes homologous to Streptococcus thermophilus. Food Microbiol. 2012;31:33-42.

32. Chen H-J, Tsai J-C, Chang T-C, Hung W-C, Tseng S-P, Hsueh P-R, et al. PCRRFLP assay for species and subspecies differentiation of the Streptococcus bovis group based on groESL sequences. J Med Microbiol. 2008;57:432-8.

33. Jans C, Lacroix C, Meile L. A novel multiplex PCR/RFLP assay for the identification of Streptococcus bovis/Streptococcus equinus complex members from dairy microbial communities based on the 16S rRNA gene. FEMS Microbiol Lett. 2012;326:144-50.

34. Enright MC, Spratt BG. A multilocus sequence typing scheme for Streptococcus pneumoniae: identification of clones associated with serious invasive disease. Microbiology. 1998;144:3049-60.

35. King SJ, Leigh JA, Heath PJ, Luque I, Tarradas C, Dowson CG, et al. Development of a multilocus sequence typing scheme for the pig pathogen Streptococcus suis: identification of virulent clones and potential capsular serotype exchange. J Clin Microbiol. 2002;40:3671-80.

36. Jones N, Bohnsack JF, Takahashi S, Oliver KA, Chan MS, Kunst F, et al. Multilocus sequence typing system for group B Streptococcus. J Clin Microbiol. 2003;41:2530-6.

37. Delorme C, Poyart C, Ehrlich SD, Renault P. Extent of horizontal gene transfer in evolution of streptococci of the salivarius group. J Bacteriol. 2007; 189:1330-41.

38. Webb K, Jolley KA, Mitchell Z, Robinson C, Newton JR, Maiden MCJ, et al. Development of an unambiguous and discriminatory multilocus sequence typing scheme for the Streptococcus zooepidemicus group. Microbiol-SGM. 2008;154:3016-24.

39. Coffey TJ, Pullinger GD, Urwin R, Jolley KA, Wilson SM, Maiden MC, et al. First insights into the evolution of Streptococcus uberis: a multilocus sequence typing scheme that enables investigation of its population biology. Appl Environ Microbiol. 2006;72:1420-8.

40. Tamura K, Peterson D, Peterson N, Stecher G, Nei M, Kumar S. MEGA5: molecular evolutionary genetics analysis using maximum likelihood, evolutionary distance, and maximum parsimony methods. Mol Biol Evol. 2011;28:2731-9.

41. Huson DH, Bryant D. Application of phylogenetic networks in evolutionary studies. Mol Biol Evol. 2006;23:254-67.

42. Jolley KA, Feil EJ, Chan MS, Maiden MCJ. Sequence type analysis and recombinational tests (START). Bioinformatics. 2001;17:1230-1.

43. Passerini D, Beltramo C, Coddeville M, Quentin Y, Ritzenthaler P, DaveranMingot ML, et al. Genes but not genomes reveal bacterial domestication of Lactococcus lactis. PLoS One. 2010;5:e15306.

44. Sawyer S. Statistical tests for detecting gene conversion. Mol Biol Evol. 1989; 6:526-38.

45. Feil EJ, Li BC, Aanensen DM, Hanage WP, Spratt BG. eBURST: inferring patterns of evolutionary descent among clusters of related bacterial genotypes from multilocus sequence typing data. J Bacteriol. 2004;186: 1518-30.

46. Spratt BG, Hanage WP, Li B, Aanensen DM, Feil EJ. Displaying the relatedness among isolates of bacterial species - the eBURST approach. FEMS Microbiol Lett. 2004;241:129-34.

47. Scally M, Schuenzel EL, Stouthamer R, Nunney L. Multilocus sequence type system for the plant pathogen Xylella fastidiosa and relative contributions of recombination and point mutation to clonal diversity. Appl Environ Microbiol. 2005;71:8491-9.

48. Carriço JA, Silva-Costa C, Melo-Cristino J, Pinto FR, de Lencastre H, Almeida JS, et al. Illustration of a common framework for relating multiple typing methods by application to macrolide-resistant Streptococcus pyogenes. J Clin Microbiol. 2006:44:2524-32

49. Grundmann H, Hori S, Tanner G. Determining confidence intervals when measuring genetic diversity and the discriminatory abilities of typing methods for microorganisms. J Clin Microbiol. 2001;39:4190-2.

50. Russell JB, Sharp WM, Baldwin RL. The effect of pH on maximum bacterial growth rate and its possible role as a determinant of bacterial competition in the rumen. J Anim Sci. 1979;48:251-5.
51. Mozzetti V, Grattepanche F, Moine D, Berger B, Rezzonico E, Arigoni F, et al. Transcriptome analysis and physiology of Bifidobacterium longum NCC2705 cells under continuous culture conditions. Benef Microbes. 2012;3:261-72.

52. Guerra A, Etienne-Mesmin L, Livrelli V, Denis S, Blanquet-Diot S, Alric M. Relevance and challenges in modeling human gastric and small intestinal digestion. Trends Biotechnol. 2012;30:591-600.

53. van Bokhorst-van de Veen $\mathrm{H}$, Lee IC, Marco ML, Wels M, Bron PA, Kleerebezem M. Modulation of Lactobacillus plantarum gastrointestinal robustness by fermentation conditions enables identification of bacterial robustness markers. PLoS One. 2012;7:e39053.

54. Roos $\mathrm{S}$, Jonsson $\mathrm{H}$. A high-molecular-mass cell-surface protein from Lactobacillus reuteri 1063 adheres to mucus components. Microbiology. 2002;148:433-42.

55. Malo N, Hanley JA, Cerquozzi S, Pelletier J, Nadon R. Statistical practice in high-throughput screening data analysis. Nat Biotechnol. 2006:24:167-75.

56. Rothman KJ. No adjustments are needed for multiple comparisons. Epidemiology. 1990;1:43-6.

57. Smith JM, Smith NH, O'Rourke M, Spratt BG. How clonal are bacteria? Proc Natl Acad Sci U S A. 1993;90:4384-8.

58. Papadimitriou K, Anastasiou R, Mavrogonatou E, Blom J, Papandreou NC, Hamodrakas SJ, et al. Comparative genomics of the dairy isolate Streptococcus macedonicus ACA-DC 198 against related members of the Streptococcus bovis/ Streptococcus equinus complex. BMC Genomics. 2014;15:272.

59. Zinsstag J, Schelling E, Waltner-Toews D, Tanner M. From "one medicine" to "one health" and systemic approaches to health and well-being. Prev Vet Med. 2011:101:148-56.

60. Montavon A, Jean-Richard V, Bechir M, Daugla DM, Abdoulaye M, Bongo Naré $\mathrm{RN}$, et al. Health of mobile pastoralists in the Sahel - assessment of 15 years of research and development. Trop Med Int Health. 2013;18:1044-52.

61. Tempia S, Braidotti F, Aden HH, Abdulle MH, Costagli R, Otieno FT. Mapping cattle trade routes in southern Somalia: a method for mobile livestock keeping systems. Rev Sci Tech. 2010;29:485-95.

62. Rusniok C, Couvé E, Da Cunha V, El Gana R, Zidane N, Bouchier C, et al. Genome sequence of Streptococcus gallolyticus: insights into its adaptation to the bovine rumen and its ability to cause endocarditis. J Bacteriol. 2010; 192:2266-76.

63. Jolley KA, Maiden MC. BIGSdb: scalable analysis of bacterial genome variation at the population level. BMC Bioinformatics. 2010;11:595

\section{Submit your next manuscript to BioMed Central and we will help you at every step:}

- We accept pre-submission inquiries

- Our selector tool helps you to find the most relevant journal

- We provide round the clock customer support

- Convenient online submission

- Thorough peer review

- Inclusion in PubMed and all major indexing services

- Maximum visibility for your research

Submit your manuscript at www.biomedcentral.com/submit
) Biomed Central 